\title{
Masculinidades que posan: dandismo, disidencia sexual y homofobia en la crónica modernista ${ }^{1}$
}

\author{
Juan Pablo Sutherland \\ Universidad Academia de Humanismo Cristiano \\ juanpablo.sutherland@gmail.com
}

\begin{abstract}
Desdeñada como frivola, ridiculizada como caricatura, o incorporada en un itinerario donde figura como etapa inicialy necesariamente imperfecta, la pose decadentista despierta escasas simpatías
\end{abstract} Silvia Molloy, La política de la pose

En una primera parte, el propósito de este trabajo reflexiona sobre las poéticas de la pose y/o dandismo latinoamericano (Sutherland, Cielo Dandi), repasando las técnicas o procedimientos de producción de las ficciones del yo en relación con el nivel discursivo de algunos textos de autores modernistas. Esa relación interesa en la medida en que toma algunos nudos críticos de la teoría de la autobiografía. ${ }^{2}$ Por otra parte, en un segundo momento nos interesa retomar algunas lecturas desde los Estudios Queer para pensar las configuraciones y las representaciones de la masculinidad y la homofobia en algunos autores modernistas. Nos interesa avanzar en una posible genealogía de la sexualidad no-normativa presente en el modernismo latinoamericano. Sexualidad y homofobia como zonas inestables de las representaciones de lo masculino en la crónica modernista.

1 Esta es una versión inicial del texto que forma parte de mi tesis doctoral en proceso Ecce Homo Dandi, Programa de Doctorado en Literatura Chilena e Hispanoamericana, Facultad de Filosofía y Humanidades, Universidad de Chile.

2 Es interesante la reflexión respecto a que la autobiografía sería una individualidad centrada. Leonel Delgado dice lo siguiente en Cartografías del yo: "En su sentido canónico, la autobiografía occidental narra la singularización y secularización de un individuo. Evidentemente, en una perspectiva histórica este sentido de individualidad -la del sujeto completado y centrado, con plenos poderes para narrarse- corresponde a estratos temporales e ideológicos específicos" (15). 


\section{Adiós a las armas}

Despatriarcar América desde la cultura

\section{Epistemología de la pose}

En su artículo "La política de la pose", Silvia Molloy comenta reflexivamente el caso de Wilde, respecto a la relevancia que adquiere el gesto de posar para la acusación que se llevará a cabo contra el escritor inglés. Según la crítica, en un primer momento se acusa a Wilde de ostentar una pose, en tiempos donde todavía no se formula la constitución, como hoy la entendemos, de un sujeto homosexual.3 Moe Moyer, citado por Molloy, señala que Wilde fue inicialmente un "preso semiótico" y no un "reo sexual". Es interesante esta problematización de Molloy en la medida en que abre el campo para re-pensar el advenimiento particular del dandismo y decadentismo europeo en América. La propuesta de lectura entiende que cierto campo de las prácticas del dandismo como fenómeno estético y social, se configura a través de una semiótica de la pose. ¿Qué relación nos interesa destacar acá? Las estrategias que realizan ciertos escritores modernistas latinoamericanos para configurar una marca propia, adquiriendo un aura de autores cosmopolitas y metropolitanos para gestionar una diferencia y generar una poética del yo.

Por otra parte, un enfoque que nos interesa re-visitar son algunas de las reflexiones que propone Michel Foucault desde su texto La Hermenéutica del sujeto. Interesa en este punto, revisar cómo se llega a producir y articular un saber y un cuidado de sí que da como resultado todo un aparato sobre la producción de los sujetos. Esta relación nos interesa en la medida en que los cronistas modernistas, a partir de sus textos y contextos, construyen una política de sí mismos que veremos reflejada en algunas biografías y textos que aquí comentaremos.

Respecto a la "cuestión del sujeto", Foucault repasa las figuras históricas que en occidente vincularon al sujeto con la verdad y que vinieron a ser desplazadas, recubiertas, negadas o hechas en nuevas racionalizaciones cuando el cristianismo se impuso, en una nueva mirada del sujeto. En ese camino, el tema de la libertad será central en la medida en que concierne a lo que somos, a lo que hacemos y a cómo nos percibimos. Campos que se vinculan directamente con el comportamiento, territorio que nos interesa transitar para nuestra problematización. Según Foucault, la moral cristiana de la abnegación, el sacrificio, es en realidad la moral que implica la renuncia de uno mismo. Será interesante desde esta perspectiva, develar ciertas técnicas internas que algunos autores como Rubén Darío o Gómez Carrillo, utilizan para promover en determinados momentos, ficciones poéticas de sí mismos.

Tomando a Max Weber, Foucault repasa la constitución de sujeto que se conformará a partir de cierta ética protestante imbricada para la construcción de sí

3 Michel Foucault en la Historia de la sexualidad: la voluntad de saber, planteará que a fines del siglo XIX se comienza a constituir un registro de lo individual asociado a ciertas prácticas que configurarán lo que hoy entendemos como sujeto homosexual. Especie surgida para Foucault como un nuevo invento del cruce entre el poder y vida, que él denominó el control bio-político de los cuerpos. 
mismo, es decir, de un sujeto posible que le servirá objetivamente al capitalismo en tanto subjetividades naturalizadas a través del trabajo y desde una ética que rodea la producción del capital. En ese horizonte observaremos cómo la modernización capitalista en algunas ciudades particulares de América Latina (Buenos Aires, México, Montevideo, Valparaíso) conjugará una vocación por la idea del progreso y la masificación de los bienes culturales. Los periódicos y diarios serán los primeros en hacer circular masivamente las nuevas modas, lecturas y protocolos sociales, que antes solo llegaban a las élites nacionales.

\section{Dandismo como práctica de soberanía individual}

A inicios del siglo XIX, en el momento cumbre de la escisión efectiva entre las clases que formaban la naciente sociedad burguesa, entre individuos e individuo, en la pulverización social impuesta por el liberalismo, entre el individuo y sí mismo, en la conculcación de lo inconsciente bajo los objetivos de la productividad, surge el breve esplendor del dandi, que se presenta elegantemente como unidad de opuestos, tesis y antítesis de sí mismo, obra inigualable de una refinación salvaje, cuya ferocidad se confunde con dulzura (Scaraffia, 81-82).

Da luces este pasaje para pensar el dandismo como un eslabón perdido de los protocolos de comportamiento individual que formaron parte de un correlato mayor, es decir, la emergencia de la sociedad burguesa en Europa. Llegando a América Latina, el dandismo tomó sus propias estrategias, y autores como Rubén Darío, Barba Jacob, Gómez Carrillo y Salvador Novo ya cruzando las vanguardias, serán quienes contribuirán a pensar un mapa propio de dandismo en América Latina. Si pensamos el dandismo como parte de una historia cultural poco estudiada, quizá debamos volver a leer ciertas claves que lo hicieron un campo cultural o un conjunto de prácticas poco populares para un tiempo de modernización y de cambio. Existió un dandismo inicial, estetizado y reflejado en cierto tipo de lecturas y con una actitud de desacato a ciertos modelos de masculinidad imperante. El dandi ante todo es una realización de una política de afectación o de pose, que desprecia la productividad burguesa leyendo a Montesquieu y Brummel, que se alzará modernizadora frente a la ruina de clases aristocráticas, de cuyo origen inicialmente arrancaron. Los dandis latinoamericanos, en su mayoría, tendrán orígenes diversos, algunos de buenas familias y otros con la sed propia de salir de la provincia y conquistar un lugar metropolitano.

Dice Mónica Bernabé:

En la confusión y cambio que envuelve el proceso de industrialización y modernización europeo, con la consecuente masificación y vulgarización, el dandy realiza una especie de performance de la individualización, articulan- 


\section{Adiós a las armas}

Despatriarcar América desde la cultura

do estrategias que le permitan fundar una aristocracia singular: El dandismo -concluye Baudelaire- es el último destello de heroísmo en las decadencias (25).

En ese preciso momento de modernización, con exposiciones universales en París, decorado en el nuevo pasatiempo del flaneo metropolitano, nos encontramos con los escritores modernistas. Rubén Darío manifiesta en su autobiografía: "Yo soñaba con París desde niño, al punto que, cuando hacía mis oraciones, rogaba a dios que no me dejase morir sin conocer París. París era para mí como un paraíso en donde respiraba la esencia de la felicidad" (69).

Es interesante reconocer en este texto autobiográfico de Darío una configuración o ficcionalización de su niñez atraída por París, capital del mundo en el siglo XIX. Ya desde este inicial paisaje reconoceremos la fuerte representación que Darío tiene de sí mismo. Es la autobiografía el vehículo para realizar esa construcción. Con su célebre publicación de Los raros, reconoceremos una coherencia estilística, su inicial recorrido por las lecturas de los decadentistas, románticos, la admiración por Verlaine, J. K. Huysmans, Wilde, Byron, Aubrey Beardsley, entre algunos, son quizá el aporte de Darío a la modernización literaria que va de la mano de la modernización liberal en algunas capitales del sur de América. Buenos Aires es el mayor ejemplo.

Ángel Rama dice: "Con el movimiento modernista dentro del cual se sitúa Darío, comienza, si no una profesionalización del artista, que por el momento era impensable, una especialización que la incipiente complejidad de algunas sociedades latinoamericanas acarrea, al generar personalidades consagradas a esa multitud de tareas que recaían en el vate" (8). Sabemos que la estadía de Darío en Buenos Aires es parte de ese contexto. Trabaja en el periódico La Nación y fue compilador de Los raros, un libro que, de alguna manera, impone cierta modernidad literaria en el continente. Ese aire fresco, irreverente, romántico, de aquellos autores, elevan a Darío en uno sus primeros divulgadores masivos. Quizá una consideración respecto a esta colección de autores dedicada a Lautréamont sea su divulgación, a la par con el liberalismo económico que coincide a su vez con la exaltación de un subjetivismo donde lo primordial es la exaltación del yo. En ese camino, Ángel Rama señala que la subjetivación refuerza el criterio de desemejanza de los hombres, abre el camino a la originalidad como principio. Contexto que hace que los valores de la innovación fortalezcan la idea de "sé tú mismo", concluye el crítico. Rama ve en el modernismo hispanoamericano una cartografía que se explica a través del desarrollo del capitalismo mundial.

Rama dice: "El modernismo hispanoamericano es parte de una crisis mundial, lo es en la medida y en el grado en que la expansión imperial de las potencias industrializadas europeas va modelando a los países del continente" (16). Es interesante dar una vuelta a esta idea de Rama en el sentido de hacer coincidir un periodo de 
producción económica con cierto tipo de producción de saber o políticas de ficción del yo en la literatura. En ese camino, se acerca además al planteamiento de Foucault respecto a la construcción de una subjetividad funcional al capitalismo. Sin embargo, estando de acuerdo con ese marco general, el modernismo resulta contradictorio como movimiento a través de sus cultores. Y creo que se pueden ver puntos de fuga de aquella productividad simbólica liberal, al incorporar como variable el dandismo y las políticas de afectación, que siendo parte del fenómeno de lo nuevo, trae consigo contradicciones dentro del propio modelo. La masculinidad como configuración cultural del sistema sexo-género impuso un modelo que refuerza la idea de lo viril, lo nacional y patriótico en la mayoría de las naciones de América Latina, la modernización no será un campo de liberalización del comportamiento moral. De alguna manera, la literatura y las artes constituirán maquinarias fundacionales de la idea de nación y prototipos de la cultura a que se aspira. El dandi como arquetipo decadente (Wilde), el homosexual como nueva especie, y las pocas mujeres "modernas", encontrarán una férrea resistencia en esta idea de lo nacional y su repertorio valórico a comienzos del siglo XX.

\section{Las contradicciones}

Darío escribe sobre Verlaine:

Mueres seguramente en uno de tus hospitales que has hecho amar a tus discípulos, tus "palacios de invierno", los lugares de descanso que tuvieron tus huesos vagabundos, en la hora de los implacables reumas y de las duras miserias parisienses.

Seguramente has muerto rodeado de los tuyos, de los hijos del espíritu, de los jóvenes oficiantes de tu iglesia, de los alumnos de tu escuela, joh, lírico Sócrates de un tiempo imposible!" (Los raros, citado en Cielo Dandi 141).

Darío cuida en extremo lo que escribe sobre Verlaine, lo cuida tanto, que el desarrollo del texto tardará para dar una semblanza cómplice del gran maestro de los decadentes y simbolistas, maestro que ha sido envuelto por la turbia sombra de degeneración. Todos conocen la relación homosexual de Verlaine con Rimbaud; Darío, en boca de otros, dirá que a Verlaine se le ha tratado como a un leproso, pero al final del poema rescatará al maestro por su obra. Como en toda su vida, Darío tendrá unas complejas actuaciones para justificarse, por admirar algunos y excusarse de sus "miserias", de alguna manera, es contradictorio más aún en América Latina, cuando las lecturas decadentes caídas en el modernismo naciente se enfrentan a una ola conservadora que ve con ojos muy sospechosos a los dandis entusiastas por estos autores y, por otra parte, se promueve la cultura helénica 


\section{Adiós a las armas}

Despatriarcar América desde la cultura

como un horizonte civilizatorio de América, ausente por cierto, de la tradición griega del cuerpo homosocial.

\section{Contención y homofobia}

Resulta interesante repasar el caso del escritor Arévalo Martínez para nuestros fines. En el famoso texto "El hombre que parecía un caballo" de su autoría, vamos a reconocer una serie de discursos presentes respecto a lo sexual, a lo masculino, que nos parecen ilustradores de cierto correlato discursivo que comparte contradictoriamente con algunos modernistas.

Dice Daniel Balderston:

Uno de los grandes "secretos abiertos" de la historia literaria hispanoamericana, la identificación de Osorio/Arenales/barba Jacob con el "señor del aretal" en el cuento de Arévalo Martínez, "El hombre que parecía un caballo" (1914) es de importancia clave para la irrupción del sujeto homosexual en esta literatura, y ejerce una función semejante a la del caso de Oscar Wilde en la literatura inglesa (36).

Es relevante la poética del escándalo y lo que narra el crítico respecto a la configuración del texto como lugar emblemático de cierta tradición homoerótica en las letras latinoamericanas. El cuento de Arévalo Martínez ha tenido el aura de haber incorporado en su narración al alter ego del conocido escritor colombiano Barba Jacob, que se destacó por ser un excéntrico y polémico escritor y con una extensa obra literaria. La narración se vuelve interesante como correlato de una homosexualidad contenida y reprimida en Guatemala en la primera década del siglo XX. El narrador cae ante la influencia de un ser enigmático, extravagante, que parecía un caballo a sus ojos, en todos sus movimientos y expresiones. El relato, cuidadosamente escrito, resulta barroco, preciosista, enrevesado y pareciera que al ser escrito el autor conocía algo de las teorías del inconsciente, pues su escritura releva ciertas miradas freudianas, quizás lo haya leído. En una parte del relato el narrador comenta:

¿Habéis oído de esos carámbanos de hielo que, arrastrados a aguas tibias por una corriente submarina, se desintegran en su base, hasta que, perdido un maravilloso equilibrio, giran sobre sí mismos en una apocalíptica vuelta, rápidos, inesperados, presentando a la faz del sol lo que antes estaba oculto entre las aguas? Así, invertidos, parecen inconscientes de los navíos que, al hundirse su parte superior, hicieron descender al abismo. Inconscientes de la pérdida de los nidos que ya se habían formado en su parte vuelta hasta entonces a la luz, en la relativa de esas dos cosas frágiles: los huevos y los hielos (8). 
La relación metafórica con la homosexualidad y sus políticas de discurso, dan cuenta en este texto, quizá a nivel simbólico, de la contención y represión que se ejerció ferozmente sobre los homosexuales en el siglo XIX y las primeras décadas del siglo XX en América Latina. Recordemos, como ya dijimos antes, el juicio a Wilde y el discurso médico e higienizante que existía en el proceso de modernización de las naciones latinoamericanas. El cuento está fechado en octubre de 1909. En este sentido, es revelador lo que dice Silvia Molloy respecto al discurso de José Ingenieros sobre la pose y la simulación: "La simulación, para Ingenieros, es una estrategia de adaptación (El mimetismo animal) en categoría moral negativa. La simulación, para Ingenieros, es una estrategia de adaptación que importa un falseo, y es por ende moralmente objetable, es un medio fraudulento de la lucha por la vida" (citado por Silvia Molloy 135).

Me interesa establecer un vínculo entre el nivel discursivo del texto de Arévalo y el planteamiento de Molloy en relación a este pánico homosexual, tanto de las institucionalidades de las épocas como de los propios escritores. En este caso, el texto trabaja con el discurso patológico de la época donde los invertidos son los homosexuales que deben permanecer ocultos. Para ello, el narrador produce una interesante estrategia, donde el lenguaje exuberante y exótico, las metáforas, la animalización del deseo homosexual contenido, operan como un gran closet que no puede ser abierto. Todo el texto, es una máquina sublimada donde no se concreta más que una suspensión del deseo, suspensión de la materialidad del cuerpo, suspensión de una identidad.

La política de la pose resulta importante como estrategia. Digo pose en la medida en que hay cierto desacato al poder, se teatraliza el deseo, pero de alguna manera se aprecia vigilado, contenido, codificado. Se convive con la pose estética y cultural para cuestionar ciertos patrones culturales y, asimismo, se le imprime una dosis de vigilancia. Quizá el escándalo que vino después con la publicación del texto, revele el temor a la exposición, la homofobia imperante y la dificultad crítica para leer el texto contaminado con la disputa entre Ricardo Arenales (Barba Jacob) y Arévalo Martínez.

El escritor colombiano era un dandi, un provocador, un polémico extravagante, pero ese ejercicio de pose, propio de los dandis, nunca trabajó con una determinada política de identidad, recordemos que lo homosexual, en aquellos tiempos, caía dentro de la patología y, por ende, de la persecución. En ese sentido, la pose es una política que tuvo lugar en un determinado contexto cultural y social, que los dandis como práctica ostentaron en diversos círculos. El cuento de Arévalo espejea a un personaje "real" que, a su vez, arrastra la leyenda del excéntrico. Es notable esta relación, pues se unen las fronteras de la pose como contención y como fuga, en momentos donde el ejercicio de la masculinidad es sinónimo de sentido patrio y de nación. 


\section{Adiós a las armas}

Despatriarcar América desde la cultura

\section{La poética de la pose en Salvador Novo}

Dice Monsiváis:

Sin proponérselo, Novo acelera entre 1920 y 1940 una nueva mirada social. Posar como sodomita. Retratarse jactancioso sin necesidad del expediente y el acta del Ministerio Público, simplemente porque le da la gana; salir a la luz del día en medio de las "ondas arcádicas" del vestuario y los gestos, contradecir a la revolución en un punto: la apariencia de la virilidad es el prerrequisito de la batalla. Novo posa como la imagen que se espera de los desviados, y al ajustarse a las ideas preconcebidas, las transciende (81).

Novo parece transitar como sujeto en una intersección, su dandismo es propio de las dos primeras décadas del siglo XX y del modernismo y, en otro sentido, a él se le puede leer dentro del espacio de las vanguardias. Novo comparte con muchos dandis latinoamericanos la extravagancia, la pose, una cultura metropolitana, un desacato al modelo de masculinidad de su tiempo. Novo y otros dandis latinoamericanos desarrollaron, tanto en sus textos como en su política de pose, una estrategia oblicua o indirecta para fugarse de lo que no se debía nombrar: la homosexualidad propia o de aquellos. Es interesante esta práctica escénica para esquivar o parodiar el género o la identidad, que se podría leer hoy, con la distancia del tiempo, como una estrategia propiamente queer. Es decir, se trabaja cierta performatividad, que se hace cargo del estigma homofóbico, de una "anormalidad abyecta” para generar una política de disidencia desde ese lugar politizado.

La política de la pose finisecular, que Molloy reivindica en su texto, cobra sentido en la perspectiva de desplazar una política de identidad a través de la teatralización, obviamente que en circunstancias distintas y por razones políticas parecidas, es decir, hacer frente a la normatividad sexo-género imperante. En el caso de Novo, hay una obvia provocación al modelo de masculinidad que promovía la revolución. Masculinidad hegemónica no solo del México revolucionario, sino de toda América Latina. Novo sabe claramente que su provocación resulta ser una estrategia barroca y política en la medida en que juega a una representación del homosexual, pero que, por otra parte, al ejercerla disuelve en el ojo que mira esa posible identidad. Es decir, es tan obvio que por lógica puede pasar como una pose excéntrica de un escritor "delicado". Todos ellos sinónimos consensuados para disminuir la abyección de una identidad no-normativa. Ya en poemas de adolescencia, Novo despliega atisbos de una política de enmascaramiento y exhibicionismo: 
Por la cruz inicial de tu nombre, Xavier

Y por la V de Vida que late en tu apellido,

Yo columbro tus ansias humildes de no ser,

Y escucho el ritmo de tu corazón encendido.

Porque tu voz es sabia en callar y ceder

Al claro simbolismo del rosal florecido;

Porque en tus manos hay aroma de mujer

$\mathrm{Y}$ en tu soñar angustia, y en tu ademán olvido.

Porque nuestras dos almas son como el cielo y el mar

Profundas e inconscientes en su grave callar

Porque lloramos mucho y rezamos en vano,

$Y$ porque nos devora un ansia pecadora

Quiero decirte: ¡sufre!, quiero decirte: ¡Llora!

Quiero decirte: ¡Ama!, quiero decirte: ¡Hermano!

(Citado en Monsiváis 75).

Esta estrategia de escritura anticipa la poética de representación que tendrá Novo públicamente. Es decir, decorar y exponer, representar y exhibir, políticas recurrentes de un dandismo latinoamericano que tuvo que esquivar en sus poses la normatividad del sistema hegemónico.

El ánimo de este texto ha sido problematizar algunos vértices de una cierta política de representación de algunos modernistas o de la escena modernista cruzada con el dandismo, una sexualidad abyecta y el contexto homofóbico de la época. Desde esta idea, nos parece que el modernismo en su interior y despliegue vivió puntos de contradicción, que lo hacen a ratos luminoso, a ratos inestable y poco homogéneo, que podrían espejearse en las actuaciones de sus integrantes.

Un elemento que destaca en los modernistas, han sido sus políticas de representación, sus desplazamientos y sus propias poéticas del yo en sus textos, cruzando los géneros. Rubén Darío en sus textos y biografía es la expresión más evidente de esa hermenéutica de sí o de esa política del yo. Finalmente recurro a Molloy para cerrar este trabajo:

Del mismo modo, creo que también "renuncia" la cultura hispanoamericana de fin de siglo pasado a asumir esas poses que durante un brevísimo momento significaron más allá de su propia simulación. Vaciadas de pertinencia, quedaron arrumbadas, como utilería en desuso, en el closet de la representación para no hablar del closet de la crítica. Creo que era justo devolverles la visibilidad que alguna vez tuvieron (134). 


\section{Adiós a las armas}

Despatriarcar América desde la cultura

\section{Obras citadas}

Arévalo Martínez, Rafael. El hombre que parecía un caballo y otros cuentos. Colección Archivos, 1997.

Bernabé, Mónica, Vida de artistas, bobemia y dandismo en Mariátegui, Valdelomar y Eguren (Lima, 1911-1922), Beatriz Viterbo Editora, 2006.

Balderston, Daniel. El deseo enorme cicatriz luminosa, Beatriz Viterbo Editora, 2004.

Darío, Rubén. Autobiografía. Afrodisio Amado, SA, 1912.

Delgado, Leonel. "Cartografías del yo. Escritura autobiográfica y modernidad en Centroamérica, del modernismo al testimonio". Tesis de doctorado, University of Pittsburgh, 2005.

Foucault, Michel. Hermenéutica del sujeto. Fondo de Cultura Económica, 2002.

Michel Foucault en la Historia de la sexualidad: la voluntad de saber. Vol 1. Siglo xxi. 2010.

Monsiváis, Carlos. Salvador Novo, lo marginal al centro. Biblioteca Era, 2000.

Molloy, Silvia. "La política de la pose". Las culturas de fin de siglo en América Latina, editado por Josefina Ludmer. Beatriz Viterbo Editora, 1994, pp. 128-138.

Rama, Ángel. Rubén Dario y el modernismo. Universidad Central de Venezuela, 1970.

Scaraffia, Giuseppe. Diccionario dandi. Antonio Machado Libros, 2009.

Sutherland, Juan Pablo. Cielo dandi, escrituras y poéticas de estilo. Eterna Cadencia, 2011.

Quiroga, José. Mapa callejero, crónicas sobre lo gay desde América latina, Eterna cadencia, 2010. 